\title{
The rationale and design of Insight into Nephrotic Syndrome: Investigating Genes, Health and Therapeutics (INSIGHT): a prospective cohort study of childhood nephrotic syndrome
}

\author{
Neesha Hussain², J Anastasia Zello ${ }^{6}$, Jovanka Vasilevska-Ristovska², Tonny M Banh ${ }^{4}$, Viral P Patel ${ }^{4}$, Pranali Patel ,
} Christopher D Battiston ${ }^{2}$, Diane Hebert ${ }^{1,4}$, Christoph P B Licht ${ }^{1,4}$, Tino D Piscione ${ }^{1,4}$ and Rulan S Parekh ${\text { 1, } 2,3,4,5^{*}}^{*}$

\begin{abstract}
Background: Nephrotic syndrome is one of the most commonly diagnosed kidney diseases in childhood and its progressive forms can lead to chronic kidney disease (CKD) and/or end-stage renal disease (ESRD). There have been few longitudinal studies among a multi-ethnic cohort to determine potential risk factors influencing disease susceptibility, treatment response, and progression of nephrotic syndrome. Temporal relationships cannot be studied through cross-sectional study design. Understanding the interaction between various factors is critical to developing new strategies for treating children with kidney disease. We present the rationale and the study design of a longitudinal cohort study of children with nephrotic syndrome, the Insight into Nephrotic Syndrome: Investigating Genes, Health and Therapeutics (INSIGHT) study. The specific aims are to determine: 1) sociodemographic, environmental, and genetic factors that influence disease susceptibility; 2) rates of steroid treatment resistance and steroid treatment dependence, and identify factors that may modify treatment response; 3) clinical and genetic factors that influence disease susceptibility and progression to CKD and ESRD; and 4) the interaction between the course of illness and socio-demographic, environmental, and clinical risk factors.
\end{abstract}

Methods/design: INSIGHT is a disease-based observational longitudinal cohort study of children with nephrotic syndrome. At baseline, participants complete questionnaires and provide biological specimen samples (blood, urine, and toenail clippings). Follow-up questionnaires and repeat biological specimen collections are performed annually for up to five years.

Discussion: The proposed cohort will provide the structure to test various risk factors predicting or influencing disease susceptibility, treatment response, and progression to CKD among children with nephrotic syndrome.

Trial registration: ClinicalTrials.gov Identifier NCT01605266.

Keywords: Children, Nephrotic syndrome, Cohort, Chronic kidney disease, FSGS, Minimal change disease, Study protocol

\footnotetext{
* Correspondence: rulan.parekh@sickkids.ca

${ }^{1}$ Division of Nephrology, The Hospital for Sick Children, 555 University

Avenue, Toronto, ON M5G 1X8, Canada

${ }^{2}$ Child Health Evaluative Sciences, Research Institute, The Hospital for Sick

Children, 555 University Avenue, Toronto, ON M5G 1X8, Canada

Full list of author information is available at the end of the article
} 


\section{Background}

Idiopathic nephrotic syndrome is a commonly diagnosed kidney disease in childhood and treatment resistant forms can result in scarring of the kidney, eventually progressing to chronic kidney disease (CKD) and/or end stage renal disease (ESRD) [1]. Nephrotic syndrome occurs when changes in the permselectivity barrier of the glomerular capillary wall can no longer restrict the loss of protein to a minimal level, thus resulting in massive protein loss through the urine [2]. Nephrotic syndrome can result in lethal infections, thrombosis, and pulmonary edema as a result of the significant protein loss [2]. The estimated incidence of nephrotic syndrome is between 2-7 per 100,000 children worldwide, with higher rates reported among those with African and South Asian ancestry [2-6]. The specific causes of nephrotic syndrome are disputed, but are considered to be immunemediated based on the evidence that steroids treat the underlying disease, and on observed associations of nephrotic syndrome with atopy. Prior to the initiation of steroid treatment in the 1960s, the risk of morbidity and mortality was extremely high [7]. Most common clinical protocols provide at least 12-16 weeks of steroid therapy at diagnosis, followed by second line agents if the child is deemed steroid resistant, steroid dependant, or a frequent relapser. Current clinical convention is that the initial response to steroids will determine the long-term risk of disease progression; however, approximately $20 \%$ of children with nephrotic syndrome will not respond to steroids among those with European ancestry, and the rates of steroid treatment resistance are reported to be significantly higher among those with African $(\approx 16-27 \%)$ and Asian ( $\approx 27-54 \%)$ ancestry (Table 1) $[2-6,17,18]$.

There have been very few longitudinal cohort studies of children with nephrotic syndrome (Table 1). Most cohort studies are retrospective chart reviews, limited by access to clinical data that have been recorded and are available. The few prospective studies on childhood nephrotic syndrome are largely registries with short follow-up time and limited clinical information. Existing cohort studies are limited to ethnically homogenous populations, which preclude the ability to test if there are true differences in treatment response among ethnicities, or if this observed difference is a result of bias from highly selected populations or differences among pediatric nephrology practices. However, this could be tested in a cohort study involving a diverse group of children treated under the same clinical protocol.

There is also an emerging picture of the role of genetics in nephrotic syndrome. In 2008, the gene, MYH9, was found to explain both the higher rates of focal segmental glomerulosclerosis (FSGS), a steroid-resistant form of nephrotic syndrome, and the higher rates of ESRD among African Americans compared to European Americans $[19,20]$. FSGS and ESRD were also linked to an adjacent gene on the chromosome 22 locus, APOL1, in 2010 [21].
The odds of having advanced kidney disease are 2-7 times greater for those carrying risk alleles of either MYH9 or APOL1, as compared to controls [19,20]. APOL1 has also been linked to HIV-associated nephropathy [22]. The chromosome 22 locus is also associated with both kidney disease susceptibility and kidney disease progression among Europeans; however, the allele frequency is low and thus cannot be used for clinical screening of progression [23]. Moreover, the APOL1 allele frequency varies depending on ancestry, but studies have yet to determine if those of Asian or South Asian heritage are at higher risk than those of other ethnic backgrounds [24]. Genetic factors may play a significant role in the development of disease among children, as there is limited time for exposure to non-genetic factors that influence disease risk as in adults.

It is likely that both genetic and environmental factors are involved in the onset and course of nephrotic syndrome. The onset of nephrotic syndrome has been linked to environmental influences such as mercury exposure (in adults), history of atopy, and immune response [25-28]. Renal effects have been found in children as a result of low-level exposures to cadmium, lead, mercury, and arsenic, but the role of these exposures in nephrotic syndrome has never been explicitly identified [29]. There is a small body of literature describing the associations between childhood nephrotic syndrome and socio-demographic factors, but they are mostly cross-sectional studies or prospective studies with limited follow-up, thus restricting our understanding of the determinants of health for children with nephrotic syndrome and their families due to limitations in study design and follow-up [30-39]. As a result, there is a significant gap in the literature on the role of environmental and socio-demographic modifiers of nephrotic syndrome in children in the long-term. Socio-demographic factors such as economic status, child quality of life and parental well-being, environmental factors such as exposures to lead or heavy metals, and serological modifiers, clinical factors such as hypertension or body mass index, or genetic factors may account for the variability in incidence and progression rates among various ethnic groups. A prospective cohort that addresses these variables would allow researchers to address temporal association to detect gene or gene-environment interactions that cannot be identified in case-control or cross-sectional study designs [40]. For example, if genetic screening in children could identify those that will have worse outcomes and an increased likelihood of progression, current clinical strategies will be challenged and alternative treatments to delay progression may be considered, such as the use of antihypertensive medications [41].

Insight into Nephrotic Syndrome: Investigating Genes, Health, and Therapeutics (INSIGHT) is a longitudinal study established to test for factors influencing disease susceptibility, treatment response, and progression to 
CKD and ESRD among children with nephrotic syndrome. Understanding the interaction between sociodemographic, environmental, clinical, and genetic factors over time is critical to developing new strategies for treating children with nephrotic syndrome. This paper describes the study design of INSIGHT, and discusses the potential implications of its research.

\section{Methods and study design}

\section{Study centre}

INSIGHT is a disease-based, observational longitudinal cohort study primarily based at The Hospital for Sick Children (SickKids) in Toronto, Canada. Since 1993, there has been a nurse-managed, out-patient program to teach patient and families self-monitoring and treatment of relapses from nephrotic syndrome. This program uses a validated electronic data system to track basic clinical information and relapses throughout the clinical followup period of each child. Staff physicians oversee the program and direct the decision-making surrounding medication dosage and patient care plans. A standard treatment protocol was implemented and developed nearly 20 years ago based on consensus of staff physicians and revised in 2000 for the treatment of relapses. The protocol involves an initial 16 weeks of steroid therapy with prednisone, comprised of a maximum of

Table 1 Observational Studies in Children with Nephrotic Syndrome

\begin{tabular}{|c|c|c|c|c|c|c|c|}
\hline Author & Year & $\mathrm{N}$ & Ethnicity & $\begin{array}{l}\text { Mean Age at Onset } \pm \\
\text { SD, yrs (Range) }\end{array}$ & Male (\%) & $\begin{array}{l}\text { Mean Follow-Up Time } \pm \\
\text { SD, yrs (Range) }\end{array}$ & $\begin{array}{c}\text { Steroid } \\
\text { Resistant (\%) }\end{array}$ \\
\hline \multicolumn{8}{|c|}{ Retrospective Studies } \\
\hline \multirow[t]{4}{*}{ Ingulli [5] } & 1991 & 177 & Black \& Hispanic & $7.3 \pm 4.6$ & No data & $8.25 \pm 4.3$ & $15.3 \%$ \\
\hline & & & & $(1.0-16.75)$ & & $(1-15)$ & \\
\hline & & 65 & Caucasian & $7.8 \pm 4.8$ & & $8.8 \pm 4.1$ & $6.2 \%$ \\
\hline & & & & $(2-14.8)$ & & $(2-14.8)$ & \\
\hline \multirow[t]{2}{*}{ Bircan [8] } & 2002 & 138 & Turkish & $4.9 \pm 3.56$ & $61.2 \%$ & $3.4 \pm 2.31$ & $13.2 \%$ \\
\hline & & & & $(1-15)$ & & $(1-6)$ & \\
\hline \multirow[t]{2}{*}{ Ozkaya [9] } & 2004 & 392 & Turkish & $4.6 \pm 3.4$ & $59.2 \%$ & 2 & $23 \%{ }^{\mathrm{b}}$ \\
\hline & & & & $(0.9-16)^{a}$ & & & \\
\hline \multirow[t]{2}{*}{ Kim [10] } & 2005 & 103 & Caucasian & $4.3 \pm 3.5$ & $51 \%$ & No data & $3.6 \%$ \\
\hline & & 96 & African-American & $8.2 \pm 5.2$ & & No data & $11 \%$ \\
\hline \multirow[t]{2}{*}{ Bhimma [3] } & 2006 & 816 & Black \& Indian & 4.8 & $60.4 \%$ & 2.5 & $27.3 \%$ \\
\hline & & & & $(1.2-16)$ & & $(0.1-16.5)$ & \\
\hline \multirow[t]{2}{*}{ Chang [11] } & 2009 & 99 & Chinese & $8.35 \pm 4.61$ & $73.7 \%$ & $5.06 \pm 4.35$ & $N / A^{e}$ \\
\hline & & & & $(2-18)$ & & & \\
\hline \multirow[t]{2}{*}{ Mubarak [6] } & 2009 & 538 & Pakistani & $9.79 \pm 4.59$ & $64.4 \%$ & No data & $31.1 \%$ \\
\hline & & & & $(0.8-18)^{a}$ & & & \\
\hline \multirow[t]{2}{*}{ Otukesh [12] } & 2009 & 73 & Iranian & 5.9 & $52.0 \%$ & $6.0 \pm 4.2$ & $100 \%$ \\
\hline & & & & & & $(0.5-16)$ & \\
\hline \multirow[t]{2}{*}{ Copelovitch [4] } & 2010 & 112 & Cambodian & 8.95 & $63.4 \%$ & 15.1 & $6.25 \%$ \\
\hline & & & & $(0.6-15.75)$ & & $(3.7-2.73)$ & \\
\hline \multirow[t]{2}{*}{ Banaszak [13] } & 2012 & 76 & Caucasian (Poland) ${ }^{c}$ & 2.7 (median) & $54.5 \%$ & No data & $15.8 \%$ \\
\hline & & 102 & Caucasian (Poland) $^{d}$ & 3.3 (median) & $68 \%$ & No data & $31.3 \%$ \\
\hline \multicolumn{8}{|l|}{ Prospective Studies } \\
\hline Kumar [14] & 2003 & 290 & Northern and Eastern Indian & $7.9 \pm 5.1$ & $73.4 \%$ & No data & $38 \%^{\mathrm{b}}$ \\
\hline Wong [15] (Registry) & 2007 & 49 & $\begin{array}{l}\text { New Zealand European, } \\
\text { Maori, Pacific Islander, Asian, Other }\end{array}$ & $6.1 \pm 3.8$ & $71.4 \%$ & 1 & $19.6 \%$ \\
\hline Bakkali [16] (Registry) & 2011 & 231 & No data (Netherlands) & 5.08 & $67.1 \%$ & 4 & $N / A^{e}$ \\
\hline
\end{tabular}

${ }^{a}$ indicates age of study group, where age at onset not specified.

b estimated based on participants diagnosed with FSGS.

c indicates patients treated with NS between 1986-1995.

${ }^{d}$ indicates patients treated with NS between 1996-2005.

e no steroid resistance reported. 
$60 \mathrm{mg} / \mathrm{m}^{2}$ per day for 6 weeks, then tapering the dose to $40 \mathrm{mg} / \mathrm{m}^{2}$ every other day for 6 weeks, $30 \mathrm{mg} / \mathrm{m}^{2}$ every other day for 8 days, $20 \mathrm{mg} / \mathrm{m}^{2}$ every other day for 8 days and finally $10 \mathrm{mg} / \mathrm{m}^{2}$ every other day for 12 days before stopping steroid treatment. A standard protocol is also used for the treatment of relapses. This is followed by second-line agents if the child is deemed steroid resistant, steroid dependant, or a frequent relapser, and is decided on a case-by-case basis.

\section{Aims}

Aims of INSIGHT are to determine 1) genetic and environmental factors that influence susceptibility to nephrotic syndrome among a multi-ethnic group of children; 2) rates of steroid treatment resistance and steroid treatment dependence, and the influence of ethnicity as a treatment modifier in children with nephrotic syndrome; 3) clinical and genetic factors that influence progression of kidney disease to CKD and/or ESRD among children

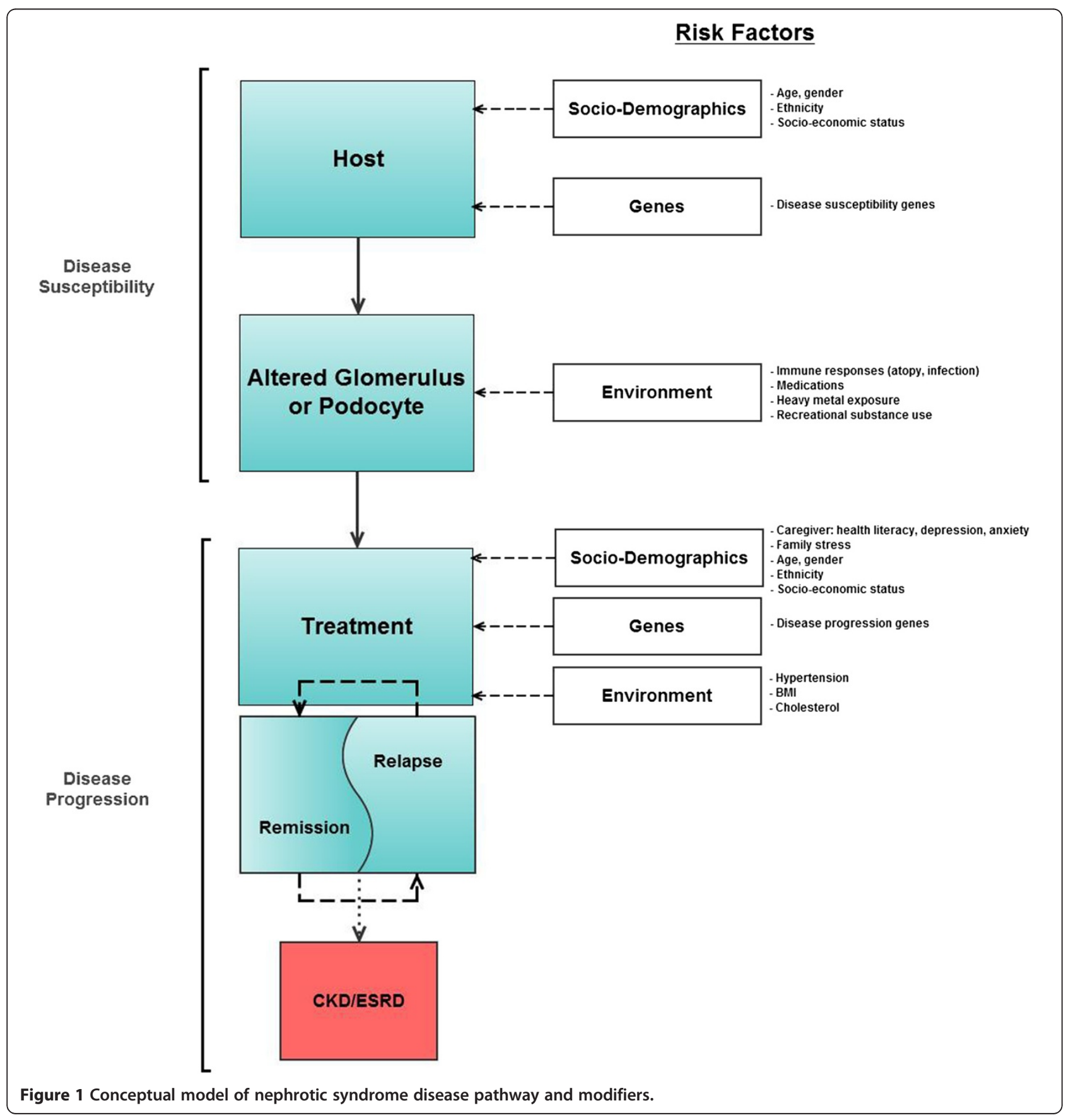


with nephrotic syndrome; and 4) the interaction between nephrotic syndrome and socio-demographic, environmental, and clinical modifiers (Figure 1).

\section{Study participants}

The study population consists of incident and prevalent cases of nephrotic syndrome diagnosed or treated at SickKids after 1993. Participants concurrently followed in clinic will be seen prospectively by the study for up to five years, or until they are discharged from clinical care. Non-concurrent participants are seen once for the study. The inclusion criteria for participants are: 1) a diagnosis of presumed idiopathic nephrotic syndrome after the age of 1 and before age 18; and 2) ability to provide informed consent or have a parent or guardian provide informed consent on their behalf; and 3) the parent and child agreeing to complete questionnaires and to provide biological samples. Exclusion criteria are: 1) disease with multiple organ involvement; or 2) conditions such as systemic lupus erythematosus or vasculitis; or 3) patients with biopsy-proven membranous glomerulonephritis (MGN) or membranoproliferative glomerulonephritis (MPGN). Toronto's ethnically and socially diverse population will allow for the recruitment of a diverse, nonhomogenous cohort of children.

\section{Data and biological specimen collection}

Baseline and follow-up questionnaires for concurrent participants are completed by the child (if able, or by the parent by proxy) and by a parent or guardian. Baseline questionnaires for the child and parent or guardian are completed upon enrollment. Follow-up questionnaires for the parent or guardian and the child are completed annually for five years, or until the child has been discharged from clinic. INSIGHT questionnaires make use of standardized questionnaires that have been tested for reliability and validity wherever possible, including the Pediatric Quality of Life Inventory (PEDSQL $\left.{ }^{\mathrm{TM}}-\mathrm{V} 4\right)$, the McMaster Family Assessment Device (FAD), the short version of the Patient Health Questionnaire for Depression and Anxiety (PHQ-4), and the Brief Test of Functional Health Literacy in Adults (S-TOFHLA) [42-46]. Non-concurrent participants complete a basic core questionnaire upon enrollment with no follow-up. Ethnicity is self-reported for the child with nephrotic syndrome, the biological parents and the biological grandparents (Additional file 1: Appendix 1).

Key clinical outcome data for all participants are abstracted from each participant's electronic medical record. Set definitions are used, according to standard clinical care. Clinical outcomes include remission, relapse, frequently relapsing nephrotic syndrome, steroid dependence, and steroid resistance $[47,48]$. Laboratory outcomes include urine protein to creatinine ratio, urine albumin to creatinine ratio, creatinine-based eGFR, and CKD/ESRD (Table 2).

Concurrent participants provide blood and urine samples in addition to 3 toenail clippings to test for environmental exposures (i.e. lead or other heavy metals such as mercury or cadmium). This method has previously been proven to be good at measuring exposures and is less invasive than extracting hair samples [49]. Baseline samples are collected as close to enrollment as possible and annually afterwards to coincide with follow-up. Concurrent participants will also perform a 24-hour ambulatory blood pressure monitor in their second year of the study to assess the presence of hypertension or prehypertension associated with nephrotic syndrome [50]. Non-concurrent participants provide biological samples at the time of enrollment. Participants who are unable to provide a blood sample may provide a saliva sample as an alternative method of DNA collection (Appendix 1).

Table 2 Outcome Ascertainment for INSIGHT

Follow up time since initial onset (months)

\begin{tabular}{lllllll}
\hline 4 & 8 & 12 & 24 & 36 & 48 & 60
\end{tabular}

\section{Clinical}

Remission: Urine protein/creatinine $<0.2$ or Albustik negative or trace for 3 consecutive days

$x \times x \times x \quad x \quad x$

Relapse: After remission, an increase in the first morning urine protein/creatinine $\geq 2$ for 3 of 5 consecutive days $x \quad x \quad x$

Frequently relapsing NS: 4 or more relapses within 1 year OR 2 or more relapses within 6 months

Steroid dependant NS: Relapse during steroid taper or within 14 days of steroid discontinuation

Steroid resistant: Inability to induce remission within 28 days of steroid therapy

\section{Laboratory}

Urine protein/creatinine: Abnormal if $>250 \mathrm{mg} / \mathrm{mmol}$

Urine albumin/creatinine: Abnormal if $>30 \mathrm{mg} / \mathrm{mol}$

Creatinine based eGFR: eGFR by modified Schwartz $\left(\mathrm{ml} / \mathrm{min} / 1.73 \mathrm{~m}^{2}\right)=\mathrm{k} \times$ height/serum creatinine

CKD/ESRD: eGFR $<60 \mathrm{ml} / \mathrm{min} / 1.73 \mathrm{~m}^{2}$ (or dialysis)

$\begin{array}{ccccccc}x & x & x & x & x & x & x \\ & & x & x & x & x & x \\ x & x & x & x & x & x & x \\ x & x & x & x & x & & \\ & & & & & & \\ x & x & x & x & x & x & x \\ x & x & x & x & x & x & x \\ x & x & x & x & x & x & x \\ & & & \text { Anytime } & & & \end{array}$




\section{Data and sample management}

Data are entered into REDCap ${ }^{\mathrm{TM}}$, a secure online data management portal designed for use in research [51]. All biological specimens are maintained through Freezerworks $^{\mathrm{TM}}$, a biospecimen management software, and stored locally. Biological specimens are aliquoted and frozen at $-80^{\circ} \mathrm{C}$. This protocol was based on guidelines developed from established biobanking best practices [52]. Genomic DNA will be extracted from the blood and saliva samples obtained from participants. Blood and urine samples will also be tested for factors that may modify treatment response, such as cytokine levels, IgE levels, or complement.

\section{Sample size \& power considerations}

Our enrollment target is at least 350 participants from SickKids and the Greater Toronto Area. We have calculated the power for a minimum sample size of 350 participants in a longitudinal analyses of time to CKD using log-rank analyses (Table 3). We demonstrate good power across the hazard ratios ranging from 1.5-3.0 and by percent exposed as compared to those unexposed to any of the potential risk factors. These values are consistent with our preliminary data of frequencies among gender and age groups of greater than 20\%. Additionally, we have assumed an alpha of 0.05 and a 10\% drop out in either group over a minimum of 3 years of follow-up. We have excellent power for hazards greater than 2.0 consistent with candidate genes association with FSGS such as APOL1.

\section{Ethical considerations}

INSIGHT has been approved by the Research Ethics Board at SickKids. Written, informed consent is obtained from each participant (the parent or guardian and the child of age to provide consent) prior to commencing any data collection for the study. All children age 13 or less provide assent to study participation in addition to parent or guardian consent. Participants are free to withdraw from the study at any time. All data collected are linked to a unique study ID number, and not to any patient identifiers. Due to the sensitive nature of biobanking DNA, only open consent is received regarding the use of DNA.
INSIGHT is also a registered study under the ClinicalTrials.gov Identifier: NCT01605266.

\section{Results}

Recruitment for INSIGHT began in 2011 at SickKids and is ongoing. As of August 13, 2012, 211 participants have been recruited into the study (Table 4).

\section{Demographic characteristics}

The mean participant age at onset of nephrotic syndrome is $5.28 \pm 3.89$ years. Males account for $60.2 \%$ of participants. Our cohort is, thus far, mostly Englishspeaking, with $69.4 \%$ of participants reporting that they always speak English at home.

Most study participants $(n=163,87.6 \%)$ were born in Canada, however over half of their parents have immigrated from elsewhere. Nearly one-third of participants are classified as from a low-income family using a cutoff of $\$ 35,000$, based on the Statistics Canada Low Income Measure in 2007 [53]. Primary caregivers are a well-educated group with on average, $14.5 \pm 3.2$ years of schooling.

\section{Ethnicity}

Participants self-reported ethnicity for the biological grandparents, parents, and the child with nephrotic syndrome into up to four of the following categories: European/Canadian/American, South Asian, Asian/Pacific Islander, African, West Indian/Caribbean, Middle Eastern, South American, and Aboriginal. A mixed background was defined as participants reporting an ethnic ancestry in more than one category. Initial ethnic classification for 185 participants for whom self-report data are available has determined that most of the study population comes from a European ethnic background ( $\mathrm{n}=77,41.6 \%)$, followed by participants of a mixed $(n=39,21.1 \%)$, or South Asian ( $n=39,21.1 \%$ ) background. The remaining are classified as Asian/Pacific Islander $(\mathrm{n}=15,8.1 \%)$ or are from other ethnic backgrounds $(n=15,8.1 \%)$. We anticipate that as enrollment increases, the ethnic makeup of our cohort will change. This will increase generalizability to other populations not as ethnically diverse as ours in Toronto.

Table 3 Power Calculation for Survival Analyses*

\begin{tabular}{|c|c|c|c|c|c|c|c|c|c|}
\hline & \multicolumn{9}{|c|}{ Proposed study population } \\
\hline & & 350 & & & & 400 & & & \\
\hline & $\%$ exposed & $10 \%$ & $20 \%$ & $30 \%$ & $40 \%$ & $10 \%$ & $20 \%$ & $30 \%$ & $40 \%$ \\
\hline \multirow[t]{3}{*}{ Hazard ratio } & 1.5 & 0.31 & 0.59 & 0.74 & 0.8 & 0.37 & 0.66 & 0.8 & 0.85 \\
\hline & 2 & 0.79 & 0.98 & 0.99 & 0.99 & 0.86 & 0.99 & 0.99 & 0.99 \\
\hline & 2.5 & 0.98 & 0.99 & 0.99 & 1 & 0.99 & 0.99 & 1 & 1 \\
\hline
\end{tabular}

*assuming an alpha of 0.05 , follow-up over 3 years, and a $10 \%$ drop out in either group. 
Table 4 Preliminary Results from INSIGHT*

\begin{tabular}{|c|c|}
\hline Description & $\mathrm{N}$ \\
\hline \multicolumn{2}{|l|}{ Child $\left(\mathrm{N}=211^{\mathrm{a}}\right)$} \\
\hline Age at diagnosis (concurrent participants) & $5.34 \pm 3.81$ years \\
\hline Age at diagnosis (non-concurrent participants) & $5.22 \pm 3.98$ years \\
\hline \multicolumn{2}{|l|}{ Socio-Demographic Variables } \\
\hline Male & $112(60.2 \%)$ \\
\hline Always speak English at home & $129(69.4 \%)$ \\
\hline Participant born in Canada & $163(87.6 \%)$ \\
\hline \multicolumn{2}{|l|}{ Ethnicity } \\
\hline European & $77(41.6 \%)$ \\
\hline Mixed & $39(21.1 \%)$ \\
\hline South Asian (India, Sri Lanka, etc) & $39(21.1 \%)$ \\
\hline Asian/Pacific Islander & $15(8.1 \%)$ \\
\hline Other & $15(8.1 \%)$ \\
\hline \multicolumn{2}{|l|}{ Past Medical History } \\
\hline Gestational duration $\geq 36$ weeks & $149(81.42 \%)$ \\
\hline Kidney problems at birth & $4(2.2 \%)$ \\
\hline $\begin{array}{l}\text { History of nephrotic syndrome: mother, father, } \\
\text { or sibling }\end{array}$ & $3(1.52 \%)$ \\
\hline History of kidney disease: mother, father, or sibling & $1(0.5 \%)$ \\
\hline History of kidney disease: extended family & $151(27.57 \%)$ \\
\hline \multicolumn{2}{|l|}{ Parent or Caregiver $(\mathrm{N}=209)$} \\
\hline \multicolumn{2}{|l|}{ Socio-Demographic Variables } \\
\hline Parent use of interpreter to complete questionnaires & $6(6.4 \%)$ \\
\hline Mother born in Canada & $84(45.4 \%)$ \\
\hline Father born in Canada & $78(42.2 \%)$ \\
\hline Families with combined income $<\$ 35,000$ & $26(27.66 \%)$ \\
\hline Years of schooling, primary caregiver & $14.5 \pm 3.2$ years \\
\hline Age of mother at birth & $31.3 \pm 9.4$ years \\
\hline
\end{tabular}

${ }^{a}$ Current as of August 14, 2012, with open enrollment.

* Numbers in this table may not add up to the specified $\mathrm{N}$ as data are not yet available for all participants.

\section{Past medical history}

Few participants report a history of kidney disease in the immediate family. $81.4 \%$ of participants had a full gestational term of 36 weeks or greater. Only $2.2 \%(n=4)$ of participants report having had a kidney problem at birth. The average age of the biological mother at birth was $31.3 \pm 9.4$ years.

\section{Discussion}

INSIGHT is a unique project that can: 1) address the natural history of nephrotic syndrome from the time of diagnosis, unlike other studies where participants are recruited based on biopsy-proven diagnosis or treatment response; 2) test the hypotheses of genetic risk factors for nephrotic syndrome, not yet done in a large, multiethnic cohort of children; and 3) increase understanding of social, clinical, and environmental factors that impact self- and family-managed chronic disease in children over the long term. The results of this study have the potential to fill these gaps in current knowledge.

Understanding how social, environmental, clinical, and genetic factors interact is important in order to truly understand the pathogenesis of disease in a diverse population of children. Nephrotic syndrome continues to be the most commonly diagnosed kidney disease in children worldwide. INSIGHT is an important and relevant project as it will challenge our current understanding of the natural history of disease in the current era of newer steroid sparing agents; in particular, the paradigm that initial response to steroid treatment is the most important indicator of disease progression [2]. Characterizing the risk of progression solely based on steroid treatment response ignores other important risk factors that are potentially modifiable and may influence overall outcome. Our current understanding of these additional risk factors is limited by previous study designs, follow-up, and use of selected populations. Furthermore, INSIGHT is a timely project due to the recent developments in genetic associations with nephrotic syndrome, and recent reports describing increased rates of disease over time [13,20,22,54,55].

Cohort studies on chronic diseases in children have allowed us to better understand natural history of disease, resulting in transformation to clinical practices. The Diabetes Chronic Complications Trial (DCCT) and its ancillary study, Epidemiology of Diabetes Interventions and Complications (EDIC), with ten years of intervention and an additional ten years of observation demonstrated that microalbuminuria could regress. This influenced how patients were counselled and treated based on the assessment of albuminuria [56,57]. Similarly, the Chronic Kidney Disease in Children (CKiD) study, currently in its sixth year and ongoing, follows children with mild to moderate chronic kidney disease for factors influencing disease progression, neurocognition, quality of life, cardiovascular health, and growth [58]. To date, CKiD has been able to develop methods for calculating glomerular filtration rate (GFR) in children more accurately, and find associations between GFR and sleep patterns, psychosocial functioning, and neurocognitive delay. These factors have not previously been recognized as significant comorbid conditions associated with early declines in kidney function [58].

Specific to nephrotic syndrome, there are a few ongoing cohort studies in progress, and it is anticipated that INSIGHT will add complementary and additional information to this body of work (see Table 5). PodoNet and the UK Registry for Rare Kidney Diseases ( $\mathrm{RaDaR})$ are both web-based registry studies on steroid resistant nephrotic syndrome, collect limited clinical data, and include genetic testing for known genes associated with childhood 
Table 5 Summary of Prospective Studies in Glomerular Research

\begin{tabular}{lcccc}
\hline Description & INSIGHT & Neptune & PodoNet & Radar \\
\hline Target N & $300^{\mathrm{a}}$ & 450 & $1472^{\mathrm{b}}$ & Not specified \\
\# of centres & $1^{\mathrm{a}}$ & 15 & 85 & Not specified \\
Length of follow-up & 60 months & 30 months & Not specified & Not specified \\
Main inclusion criteria & $\begin{array}{c}\text { Presumed idiopathic } \\
\text { nephrotic syndrome }\end{array}$ & $\begin{array}{c}\text { Nephrotic syndrome- } \\
\text { indicated renal biopsy }\end{array}$ & $\begin{array}{c}\text { Steroid resistant } \\
\text { nephrotic syndrome }\end{array}$ Steroid resistant \\
nephrotic syndrome
\end{tabular}

\section{Child Data}

Demographics

Ethnicity \& immigration

Birth history

Child allergy history

Child comorbidity history (fever, viral illness, TB, jaundice, malaria)

Medication adherence

McMaster Family Assessment Device (FAD)

Reproductive history

Health behaviour and social history (i.e. substance use)

Quality of life

PROMIS Survey

Beck Depression Inventory

Modified Mini-Mental State Exam

\section{Parent or Caregiver Data}

Demographics

Ethnicity \& immigration

Family Environment

McMaster Family Assessment Device (FAD)

Patient Health Questionnaire for Depression and Anxiety (PHQ-4)

Pregnancy information \& assessment of in-utero exposures

Parent perspectives on genetic testing

Shortened Test of Functional Health Literacy Assessment (S-TOFHLA)

\section{Biorepository \& Clinical Information}

Ongoing assessment of relapses

Medications history and changes

Standardized genetic workup

Blood collection

Urine collection

Nail clipping

Clinical progress (unspecified)
Family medical history

\section{$x$}

$x$

$x$

$x$

${ }^{a}$ With ongoing recruitment and expansion

${ }^{\text {b }}$ Current enrollment, unspecified target.

c Presumed MCNS, FSGS, MGN, MPGN.

$\begin{array}{cccc}\text { x } & \text { Not specified } & & \text { Not specified } \\ \times & x & x & \text { Not specified } \\ x & x & x & x \\ x & x & x & \\ x & x & & x \\ x & x & x & \end{array}$


nephrotic syndrome and steroid resistance $[59,60]$. The Nephrotic Syndrome Study Network (NEPTUNE) is a prospective observational study where data collection begins at the time of a clinically indicated renal biopsy, after which they are followed for 30 months [61]. NEPTUNE and INSIGHT both assess quality of life and other socio-demographic and environmental factors that may influence, or be influenced by the progression of disease. PodoNet, $\mathrm{RaDaR}$, and NEPTUNE all focus on those with established progressive disease sufficient to warrant a biopsy, however, at this point worse disease outcomes and factors likely influencing response may be missed. INSIGHT recruits patients from the time of diagnosis with idiopathic nephrotic syndrome, and follows the natural history of the disease course (Table 5).

INSIGHT is also the only study that examines the social determinants of health among children with nephrotic syndrome. The role of socio-demographic and psychosocial factors have been shown or hypothesized to influence health status among ESRD patients but there are few observational cohort studies on children to explore the role of these factors in the earlier stages of kidney disease before progression becomes a serious concern $[62,63]$. As nephrotic syndrome in children is largely managed at home, we are further limited by a dearth of literature on interactions between a child and caregiver. INSIGHT will help fill these gaps to help us understand socio-demographic factors that influence nephrotic syndrome, or are themselves influenced by disease progression.

There are limitations to the study which should be addressed. As with all studies collecting questionnaire data with personal and often sensitive information, some participants may be unwilling to provide information and will have limited data. This study uses validated and reliable questionnaires as much as possible in order to minimize the risk of inaccuracy and reduce the risk of measurement bias. Since not all participants will get a biopsy, we can only presume their pathological diagnosis is minimal change disease based on estimates from prior studies [17]. The strengths of INSIGHT are its large projected sample size, its lengthy projected follow-up time period, and its ethnically, socially, and clinically diverse cohort, reflecting the diverse makeup of Toronto. INSIGHT actively collects information from both the parent and the child, allowing us to generate a holistic picture of the role of the family and caregivers in the treatment of nephrotic syndrome. The open enrollment structure allows us to capture participants close to the time of clinical presentation, with the aim of being able to establish factors that truly influence the immediate progression of mild disease to more serious or chronic kidney disease.

Currently, INSIGHT is based in Toronto and efforts are underway to expand the study to several partner sites within Canada and internationally to allow for a large, ethnically diverse study population. As the study expands, we anticipate that the ethnic makeup of our cohort will become increasingly diverse, thus allowing us to better test hypotheses of ethnic associations with disease. Establishing a global, multi-ethnic cohort requires some flexibility in the core data that can reasonably collected at each site, particularly in sites in low- to middle-income countries where infrastructure to facilitate clinical research may be minimal or non-existent and follow-up of participants may be more difficult.

Understanding the interaction between socio-demographic, environmental, clinical, and genetic factors associated with disease susceptibility, steroid treatment resistance and disease progression could lead to better screening strategies at initial clinical presentation and ultimately more refined treatment strategies overall. Results from INSIGHT will lead to a better understanding of nephrotic syndrome in the current era.

\section{Additional file}

Additional file 1: Appendix 1. Schedule of Data and Specimen Collection by Cohort and Visit.

\section{Abbreviations \\ ESRD: End-stage renal disease; FSGS: Focal segmental glomerulosclerosis; INSIGHT: Insight into Nephrotic Syndrome Investigating Genes, Health and Therapeutics; MGN: Membranous glomerulonephritis; \\ MPGN: Membranoproliferative glomerulonephritis; SRNS: Steroid-resistant nephrotic syndrome; GFR: Glomerular filtration rate; NEPTUNE: Nephrotic Syndrome Study Network; DCCT: Diabetes Chronic Complications Trial; EDIC: Epidemiology of Diabetes Interventions and Complications; CKid: Chronic Kidney Disease in Children Study.}

\section{Competing interests}

The authors declare that they have no competing interests.

\section{Authors' contributions}

RP designed the study. AZ drafted the manuscript. NH, RP, and TP revised the manuscript for important intellectual content. $\mathrm{NH}, J \mathrm{~V}, \mathrm{~TB}$, and VP acquired the data. PP processes the biological specimens. RP, NH, and JV obtained funding. $C B$ performed the statistical analysis. $\mathrm{DH}$, and $\mathrm{CL}$ provided intellectual input and oversight. All authors read and approved the final manuscript.

\section{Authors' information}

$\mathrm{NH}$ and $\mathrm{JV}$ are clinical research staff at SickKids. AZ is a research program summer student. TB and VP are research students. PP is the research technologist. CB is a data analyst. DH, CL, TP and RP are all staff nephrologists at SickKids.

\section{Acknowledgements}

We gratefully acknowledge funding from the Hospital for Sick Children Research Institute and Physicians' Services Incorporated (PSI). We would also like to extend our thanks to the participants and their families for their time and effort, as well as the nurses and staff from the Nephrology Clinic at SickKids, particularly Josie Brooke, Kim Aitken, Michelle Reddon and Monica Piekut. We would also like to thank Richard Child for his advice and insight into the electronic patient record.

\section{Author details}

'Division of Nephrology, The Hospital for Sick Children, 555 University Avenue, Toronto, ON M5G 1X8, Canada. ${ }^{2}$ Child Health Evaluative Sciences, Research Institute, The Hospital for Sick Children, 555 University Avenue, 
Toronto, ON M5G 1X8, Canada. ${ }^{3}$ University Health Network, 190 Elizabeth Street, Toronto, ON M5G 2C4, Canada. ${ }^{4}$ University of Toronto, 27 King's College Circle, Toronto, ON M5S 1A1, Canada. ${ }^{5}$ Dalla Lana School of Public Health, University of Toronto, 27 King's College Circle, Toronto, ON M5S 1A1, Canada. ${ }^{6}$ University of Saskatchewan, 105 Administration Place, Saskatoon, SK S7N 5A2, Canada. 'Genetic and Genome Biology, Research Institute, The Hospital for Sick Children, 555 University Avenue, Toronto, ON M5G 1X8, Canada.

Received: 28 November 2012 Accepted: 10 January 2013

Published: 26 January 2013

\section{References}

1. ISKDC: Primary nephrotic syndrome in children: clinical significance of histopathologic variants of minimal change and of diffuse mesangial hypercellularity. A Report of the International Study of Kidney Disease in Children. Kidney Int 1981, 20(6):765-771.

2. Eddy AA, Symons JM: Nephrotic syndrome in childhood. Lancet 2003, 362(9384):629-639.

3. Bhimma R, Adhikari M, Asharam K: Steroid-resistant nephrotic syndrome: the influence of race on cyclophosphamide sensitivity. Pediatr Nephrol 2006, 21(12):1847-1853.

4. Copelovitch L, Sam Ol O, Taraquinio S, Chanpheaktra N: Childhood nephrotic syndrome in Cambodia: an association with gastrointestinal parasites. J Pediatr 2010, 156(1):76-81.

5. Ingulli E, Tejani A: Racial differences in the incidence and renal outcome of idiopathic focal segmental glomerulosclerosis in children. Pediatr Nephrol 1991, 5(4):393-397.

6. Mubarak M, Lanewala A, Kazi Il, Akhter F, Sher A, Fayyaz A, Bhatti S: Histopathological spectrum of childhood nephrotic syndrome in Pakistan. Clin Exp Nephrol 2009, 13(6):589-593.

7. Soyka LF: Treatment of the nephrotic syndrome in childhood: Use of an alternate-day prednisone regimen. Arch Pediatr Adolesc Med 1967, 113(6):693-701.

8. Bircan Z, Yavuz Yilmaz A, Katar S, Vitrinel A, Yildirim M: Childhood idiopathic nephrotic syndrome in Turkey. Pediatr Int 2002, 44(6):608-611.

9. Ozkaya N, Cakar N, Ekim M, Kara N, Akkok N, Yalcinkaya F: Primary nephrotic syndrome during childhood in Turkey. Pediatr Int 2004, 46(4):436-438

10. Kim JS, Bellew CA, Silverstein DM, Aviles DH, Boineau FG, Vehaskari VM: High incidence of initial and late steroid resistance in childhood nephrotic syndrome. Kidney Int 2005, 68(3):1275-1281.

11. Chang JW, Tsai HL, Wang HH, Yang LY: Clinicopathological features and prognosis of Chinese children with idiopathic nephrotic syndrome between different age groups. Eur J Pediatr 2009, 168(10):1189-1194.

12. Otukesh H, Otukesh S, Mojtahedzadeh M, Hoseini R, Fereshtehnejad SM, Riahi Fard A, Sadigh N, Heshmatzade Behzadi A, Javadi R, Hooman N, et al: Management and outcome of steroid-resistant nephrotic syndrome in children. Iran J Kidney Dis 2009, 3(4):210-217.

13. Banaszak B, Banaszak P: The increasing incidence of initial steroid resistance in childhood nephrotic syndrome. Pediatr Nephrol 2012, 27(6):927-932

14. Kumar J, Gulati S, Sharma AP, Sharma RK, Gupta RK: Histopathological spectrum of childhood nephrotic syndrome in Indian children. Pediat Nephrol 2003, 18(7):657-660.

15. Wong W: Idiopathic nephrotic syndrome in New Zealand children, demographic, clinical features, initial management and outcome after twelve-month follow-up: results of a three-year national surveillance study. J Paediatr Child Health 2007, 43(5):337-341.

16. El Bakkali L, Rodrigues Pereira R, Kuik DJ, Ket JC, Van Wijk JA: Nephrotic syndrome in The Netherlands: a population-based cohort study and a review of the literature. Pediatr Nephrol 2011, 26(8):1241-1246.

17. ISKDC: The primary nephrotic syndrome in children. Identification of patients with minimal change nephrotic syndrome from initial response to prednisone. A report of the International Study of Kidney Disease in Children. J Pediatr 1981, 98(4):561-564.

18. Nephrotic syndrome in children: prediction of histopathology from clinical and laboratory characteristics at time of diagnosis. A report of the International Study of Kidney Disease in Children. Kidney Int 1978, 13(2):159-165.
19. Kao WH, Klag MJ, Meoni LA, Reich D, Berthier-Schaad Y, Li M, Coresh J, Patterson N, Tandon A, Powe NR, et al: MYH9 is associated with nondiabetic end-stage renal disease in African Americans. Nat Genet 2008, 40(10):1185-1192.

20. Kopp JB, Smith MW, Nelson GW, Johnson RC, Freedman BI, Bowden DW, Oleksyk T, McKenzie LM, Kajiyama H, Ahuja TS, et al: MYH9 is a major-effect risk gene for focal segmental glomerulosclerosis. Nat Genet 2008, 40(10):1175-1184.

21. Genovese G, Friedman DJ, Ross MD, Lecordier L, Uzureau P, Freedman BI, Bowden DW, Langefeld CD, Oleksyk TK, Uscinski Knob AL, et al: Association of trypanolytic ApoL1 variants with kidney disease in African Americans. Science 2010, 329(5993):841-845.

22. Kopp JB, Nelson GW, Sampath K, Johnson RC, Genovese G, An P, Friedman D, Briggs W, Dart R, Korbet S, et al: APOL1 Genetic Variants in Focal Segmental Glomerulosclerosis and HIV-Associated Nephropathy. J Am Soc Nephrol 2011, 22(11):2129-2137.

23. O'Seaghdha CM, Parekh RS, Hwang S-J, Li M, Köttgen A, Coresh J, Yang Q, Fox CS, Kao WHL: The MYH9/APOL1 region and chronic kidney disease in European-Americans. Hum Mol Genet 2011, 20(12):2450-2456.

24. Oleksyk TK, Nelson GW, An P, Kopp JB, Winkler CA: Worldwide distribution of the MYH9 kidney disease susceptibility alleles and haplotypes: evidence of historical selection in Africa. PLoS One 2010, 5(7):e11474.

25. George CR: Mercury and the kidney. J Nephrol 2011, 24(Suppl 17):S126-S132.

26. Meadow SR, Sarsfield JK: Steroid-responsive and nephrotic syndrome and allergy: clinical studies. Arch Dis Child 1981, 56(7):509-516.

27. Jahan I, Hanif M, Ali MA, Waliullah SM, Mia AH: Relationship between serum IgE and frequent relapse idiopathic nephrotic syndrome. Mymensingh medical journal: MMJ 2011, 20(3):484-489.

28. Cheung W, Wei CL, Seah CC, Jordan SC, Yap HK: Atopy, serum IgE, and interleukin-13 in steroid-responsive nephrotic syndrome. Pediatr Nephrol 2004, 19(6):627-632.

29. de Burbure C, Buchet JP, Leroyer A, Nisse C, Haguenoer JM, Mutti A, Smerhovsky Z, Cikrt M, Trzcinka-Ochocka M, Razniewska G, et al: Renal and neurologic effects of cadmium, lead, mercury, and arsenic in children: Evidence of early effects and multiple interactions at environmental exposure levels. Environ Health Perspect 2006, 114(4):584-590.

30. Vance JC, Fazan LE, Satterwhite B, Pless IB: Effects of nephrotic syndrome on the family: A controlled study. Pediatrics 1980, 65(5):948-955.

31. Vance JC, Pless IB: The effect of chronic nephrotic syndrome on the affected child. J Dev Behav Pediatr 1983, 4(3):159-162.

32. Naidoo LR, Moodley TY, Coovadia HM, Adhikari M: Neural deficits, intelligence, maladjustment and family response in children with the nephrotic syndrome. Samj S Afr Med J 1987, 71(1):9-10.

33. Mehta M, Bagga A, Pande P, Bajaj G, Srivastava RN: Behavior problems in nephrotic syndrome. Indian Pediatr 1995, 32(12):1281-1286.

34. Soliday E, Lande MB: Family structure and the course of steroid-sensitive nephrotic syndrome. Pediatr Nephrol 2002, 17(1):41-44.

35. Soliday E, Moore KJ, Lande MB: Daily reports and pooled time series analysis: Pediatric psychology applications. J Pediatr Psychol 2002. 27(1):67-76.

36. Hall AS, Thorley G, Houtman PN: The effects of corticosteroids on behavior in children with nephrotic syndrome. Pediatr Nephrol 2003, 18(12):1220-1223.

37. Ruth EM, Landolt MA, Neuhaus TJ, Kemper MJ: Health-related quality of life and psychosocial adjustment in steroid-sensitive nephrotic syndrome. J Pediatr 2004, 145(6):778-783.

38. Guha P, De A, Ghosal M: Behavior profile of children with nephrotic syndrome. Indian Journal of Psychiatry 2009, 51(2):122-126.

39. Mitra $S$, Banerjee $S$ : The impact of pediatric nephrotic syndrome on families. Pediatr Nephrol 2011, 26(8):1235-1240.

40. Wright RO, Christiani D: Gene-environment interaction and children's health and development. Curr Opin Pediatr 2010, 22(2):197-201.

41. Lipkowitz MS, Freedman BI, Langefeld CD, Comeau ME, Bowden DW, Kao WHL, Astor BC, Bottinger EP, lyengar SK, Klotman PE, et al: Apolipoprotein L1 gene variants associate with hypertension-attributed nephropathy and the rate of kidney function decline in African Americans. Kidney Int 2013, 83(1):114-120

42. Varni JW, Seid M, Kurtin PS: PedsQL 4.0: reliability and validity of the Pediatric Quality of Life Inventory version 4.0 generic core scales in healthy and patient populations. Med Care 2001, 39(8):800-812. 
43. Byles J, Byrne C, Boyle MH, Offord DR: Ontario Child Health Study: reliability and validity of the general functioning subscale of the McMaster Family Assessment Device. Fam Process 1988, 27(1):97-104.

44. Kroenke K, Spitzer RL, Williams JBW, Lowe B: An Ultra-Brief Screening Scale for Anxiety and Depression: The PHQ-4. Psychosomatics 2009, 50(6):613-621.

45. Lowe B, Wahl I, Rose M, Spitzer C, Glaesmer H, Wingenfeld K, Schneider A, Brahler E: A 4-item measure of depression and anxiety: Validation and standardization of the Patient Health Questionnaire-4 (PHQ-4) in the general population. J Affect Disord 2010, 122(1-2):86-95.

46. Baker DW, Williams MV, Parker RM, Gazmararian JA, Nurss J: Development of a brief test to measure functional health literacy. Patient Educ Couns 1999, 38(1):33-42.

47. Gipson DS, Massengill SF, Yao L, Nagaraj S, Smoyer WE, Mahan JD, Wigfall $D$, Miles P, Powell L, Lin JJ, et al: Management of childhood onset nephrotic syndrome. Pediatrics 2009, 124(2):747-757.

48. Hogg RJ, Portman RJ, Milliner D, Lemley KV, Eddy A, Ingelfinger J: Evaluation and management of proteinuria and nephrotic syndrome in children: recommendations from a pediatric nephrology panel established at the National Kidney Foundation conference on proteinuria, albuminuria, risk, assessment, detection, and elimination (PARADE). Pediatrics 2000, 105(6):1242-1249.

49. Wilhelm M, Hafner D, Lombeck I, Ohnosorge FK: Monitoring of cadmium, copper, lead and zinc status in young children using toenails: comparison with scalp hair. Sci Total Environ 1991, 103(2-3):199-207.

50. Urbina E, Alpert B, Flynn J, Hayman L, Harshfield GA, Jacobson M, Mahoney L, McCrindle B, Mietus-Snyder M, Steinberger J, et al: Ambulatory blood pressure monitoring in children and adolescents: recommendations for standard assessment: a scientific statement from the American Heart Association Atherosclerosis, Hypertension, and Obesity in Youth Committee of the council on cardiovascular disease in the young and the council for high blood pressure research. Hypertension 2008, 52(3):433-451.

51. Harris PA, Taylor R, Thielke R, Payne J, Gonzalez N, Conde JG: Research electronic data capture (REDCap) - A metadata-driven methodology and workflow process for providing translational research informatics support. J Biomedical Informatics 2009, 42(2):377-381.

52. : 2008 Best Practices for Respositories: collection, storage, retrieval and distribution of biological materials for research: International Society for Biological and Environmental Repositories (ISBER). Cell Preserv Technol 2008, 6(1):5+.

53. Canada S: In Low Income Lines, 2010 to 2011, Volume 75F0002M. Edited by Industry. Ottawa: Authority of the Minister Responsible for Statistics Canada; 2012:28-30.

54. Otukesh H, Ghazanfari B, Fereshtehnejad SM, Bakhshayesh M, Hashemi M, Hoseini R, Chalian M, Salami A, Mehdipor L, Rahiminia A: NPHS2 mutations in children with steroid-resistant nephrotic syndrome. Iran J Kidney Dis 2009, 3(2):99-102.

55. Hinkes BGMB, Vlangos CN, Gbadegsin R, Liu J, Hasselbacher K, Hangan D, Ozaltin F, Zenker M, Hildebrandt and members of the Arbeitsgemeinschaft fur Paediatrische Nephologie Study Group: Nephrotic Syndrome in the First Year of life: Two Thirds of Cases are Caused by Mutations in 4 Genes (NPHS1, NPHS2, WT1 and LAMB2). Paediatrics Int 2007, 119(4):907-919.

56. Murray P, Chune G, Raghavan V: Legacy Effects from DCCT and UKPDS: What They Mean and Implications for Future Diabetes Trials. Curr Atheroscler Rep 2010, 12(6):432-439.

57. Genuth S, Nathan D, Shamoon H, Duffy H, Dahms B, Mayer L, Brillion D, Lackaye M, Whitehouse F, Kruger D, et al: Epidemiology of Diabetes Interventions and Complications (EDIC): Design, implementation, and preliminary results of a long-term follow-up of the Diabetes Control and Complications Trial cohort. Diabetes Care 1999, 22(1):99-111.

58. Copelovitch L, Warady BA, Furth SL: Insights from the Chronic Kidney Disease in Children (CKiD) Study. Clin J Am Soc Nephrol 2011, 6(8):2047-2053.

59. Clinical Registry of SRNS Patients. http://www.podonet.org/opencms/ opencms/podonet/podonet_en/PodoNet_Projects/ Clinical_Registry_Of_SRNS_Patients.html.

60. RaDaR: www.renalradar.org.

61. Nephrotic Syndrome Study Network. https://rarediseasesnetwork.epi.usf.edu/ NEPTUNE/index.htm.
62. Cukor D, Cohen SD, Peterson RA, Kimmel PL: Psychosocial Aspects of Chronic Disease: ESRD as a Paradigmatic Illness. J Am Soc Nephrol 2007, 18(12):3042-3055.

63. Barlow JH, Ellard DR: The psychosocial well-being of children with chronic disease, their parents and siblings: an overview of the research evidence base. Child Care Health Dev 2006, 32(1):19-31.

doi:10.1186/1471-2369-14-25

Cite this article as: Hussain et al:: The rationale and design of Insight into Nephrotic Syndrome: Investigating Genes, Health and Therapeutics (INSIGHT): a prospective cohort study of childhood nephrotic syndrome. BMC Nephrology 2013 14:25.

\section{Submit your next manuscript to BioMed Central and take full advantage of:}

- Convenient online submission

- Thorough peer review

- No space constraints or color figure charges

- Immediate publication on acceptance

- Inclusion in PubMed, CAS, Scopus and Google Scholar

- Research which is freely available for redistribution 